\title{
Seizure Worsening During Pregnancy
}

\section{Who Is at Risk?}

Steven Karceski, MD

Neurology ${ }^{\circledR}$ 2022;98:e876-e879. doi:10.1212/WNL.0000000000013286

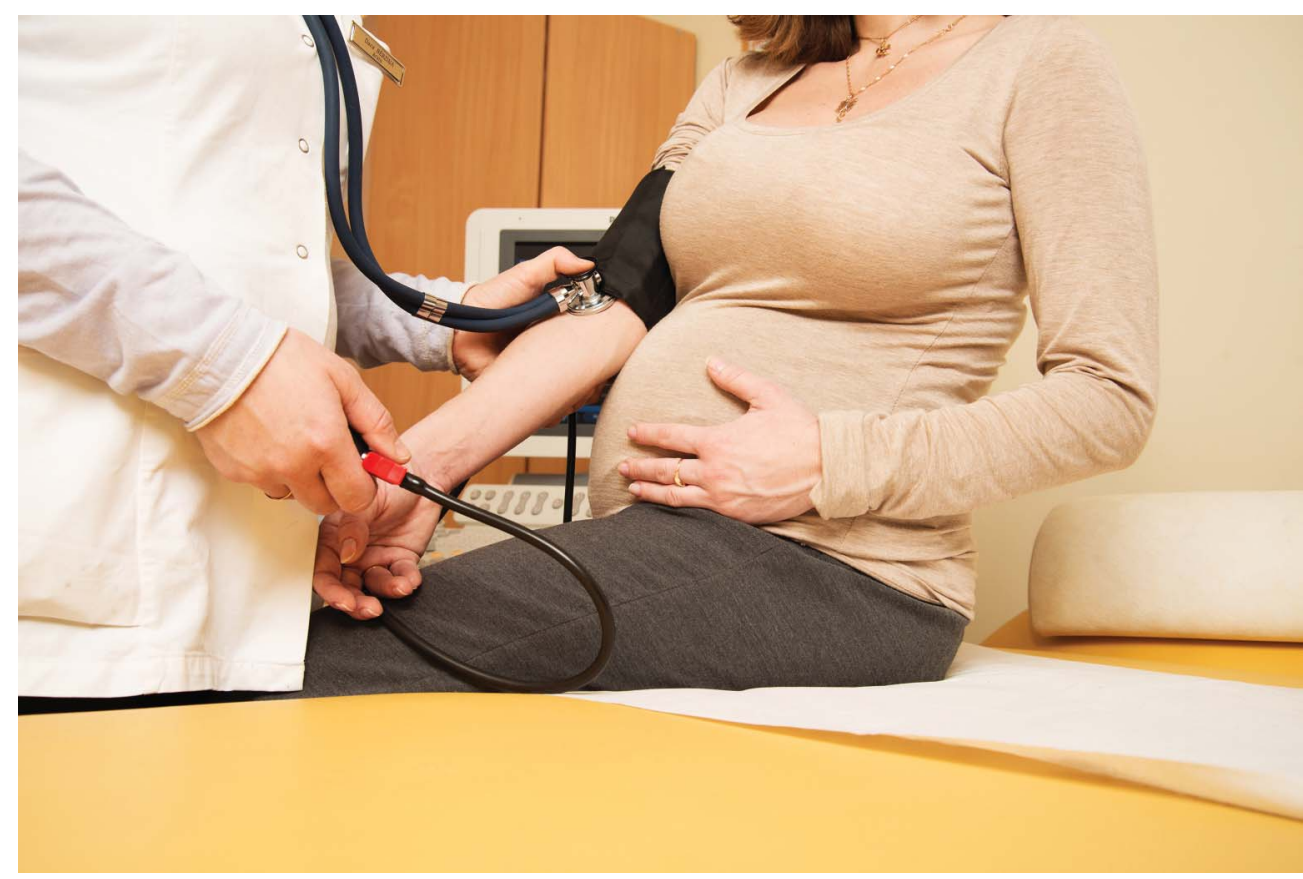

In all people with epilepsy, the goal of treatment is to stop seizures. In pregnant people, control of seizures in pregnancy protects the baby against injury and reduces the risk of premature labor and delivery. This being said, it has long been recognized that in general, women with epilepsy can have a worsening of seizures during their pregnancy. ${ }^{1}$ Less is known about the connection between the type of epilepsy and seizure worsening in pregnancy. In an article featured in this issue, "Variations in Seizure Frequency During Pregnancy and Postpartum by Epilepsy Type," Dr. Voinescu and colleagues ${ }^{2}$ studied a group of pregnant women with epilepsy to better understand this connection.

\section{How Was the Study Done?}

Between 2011 and 2019, Dr. Voinescu and colleagues at Brigham and Women's Hospital carefully studied 99 women with epilepsy over the course of 114 pregnancies. To assess seizure changes, the researchers measured the number of seizures each woman experienced in the 9 months before pregnancy began. This was referred to as the baseline seizure frequency. They then compared the prepregnancy seizure rates to the frequency of seizures during pregnancy. They also compared this baseline to each study participant's seizure frequency during the 6-9 months after the baby was born (the postpartum period).

The researchers divided the group of study participants in several ways. First, they divided the women with epilepsy into 2 groups: those who had generalized epilepsy and those who had partial epilepsy. Next, they separated the women with partial epilepsy into smaller groups based on the location of their seizure onset. For instance, did the seizures begin in the temporal lobe of the brain? The frontal lobe? How did these factors relate to seizure worsening during pregnancy? Next, they looked at the antiseizure medications the study participants were taking and how these influenced seizure worsening. Were seizures more likely to increase if a person was on 1 or more medicines?

\section{Related Article}

\section{Variations in Seizure Frequency During Pregnancy and Postpartum by Epilepsy Type}

http://dx.doi.org/10.1212/ WNL.0000000000013056 


\section{What Were the Results?}

The women who participated in the study were between the ages of 20 and 44 . A total of 37 had generalized epilepsy and 62 had focal (also called partial) epilepsy. Of the women with partial epilepsy, 15 had seizures that started in the frontal lobe. A total of 47 had seizures that started elsewhere, although most of that group had seizures that started in the temporal lobe. At the time of conception, 3 participants were taking no antiseizure medications, 100 were taking 1 medicine, and 11 were taking 2 or more medicines (these numbers add up to more than the total of 99 participants; although there were 99 women participating in the study, the women experienced a total of 114 pregnancies over the course of the study). Dr. Voinescu and colleagues looked at the type of medicines the study participants were taking. Of the pregnancies experienced by women taking 1 medicine, 2 antiseizure medications were most often used. A total of 62 participants were taking lamotrigine and 25 were taking levetiracetam. The rest were taking carbamazepine, oxcarbazepine, or zonisamide.

With regard to type of epilepsy, women with partial epilepsy (21.1\%) were much more likely to experience an increase in seizures compared to those with generalized epilepsy (5.3\%). If the seizures started in the frontal lobe, the chance of worsening seizures was $52.9 \%$. In other words, if a woman has partial epilepsy, she has a $21 \%$ chance of seizures getting worse while she is pregnant, and if the partial seizures are frontal, the chance of seizure worsening is even higher. The authors also looked at when the partial seizures were most likely to increase and found that seizure worsening tended to occur in the first and second trimesters.

In the postpartum period, seizures also worsened. In women with generalized epilepsy, worsening occurred in 9.1\%. In women with generalized epilepsy, worsening occurred in $11.1 \%$. In comparing the 2 types of epilepsy, the researchers found there was no significant difference in seizure worsening in the 6- to 9-month postpartum period.

The authors compared seizure worsening in women taking only 1 medicine (monotherapy) vs those taking more than 1 medicine (polytherapy). Women who were on polytherapy were 8 times more likely to experience seizure worsening than those on monotherapy.

\section{How Is This Important?}

When counseling women with epilepsy about pregnancy, doctors review many topics. One of them is the possibility of seizure worsening. Prior studies have described this concern. However, these studies did not show the relationship between the kind of epilepsy and seizure worsening. Furthermore, no previous study has shown the association between frontal lobe epilepsy and seizure worsening during pregnancy. Studies like this one help doctors and patients define areas of concern. With more information, especially when it comes to explaining how these things are connected, doctors may be able to modify treatments to prevent seizure worsening from occurring during pregnancy. 


\section{About Epilepsy}

\section{What Is a Seizure?}

Nerve cells talk to each other constantly. They do this by sending signals and messages to each other. These messages are both electrical and chemical (the chemical messages are called neurotransmitters). Sometimes, brain cells send the wrong messages. Our brains have their own autocorrect for these messages, but just like with a cell phone, sometimes an error goes through. When the wrong signal is sent, other brain cells respond to the error by sending abnormal signals. If enough brain cells start sending the same incorrect message, a seizure results.

One way to think of this is that the brain works like an orchestra. There are different sections in an orchestra, each with its own instruments. Although each instrument plays its own part, it is only when they all play together that complex music is made. While playing, each member of the orchestra has to listen to the other members. As a team, playing together and listening to one another, the best music is made. However, what if one person began playing a different tune? At first, no one would notice. But soon, nearby orchestra members would become confused: which tune were they supposed to play? As more members of the orchestra began playing the different tune, it would eventually become noticeable. At some point, the different tune might become louder than the original music.

This is similar to how a seizure gets started and how it keeps going. The brain cells near the cells that are playing the wrong tune start playing it as well, and they encourage other brain cells to do the same thing. Eventually, a person cannot stay aware of what is going on because too many brain cells are busy doing something else: having a seizure.

\section{What Is Epilepsy?}

Epilepsy is not just one uniform illness. There are many kinds of epilepsy. In addition, there are many possible causes of epilepsy. Just as there are many kinds of epilepsy, there are many kinds of seizures. The older definition of epilepsy is that a person has had 2 or more unprovoked seizures in lifetime. The more modern definition of epilepsy includes people who have had 1 seizure and are at very high risk of having another.

\section{How Is Epilepsy Diagnosed?}

The doctor will need to know as much as possible about what happened immediately before, during, and after a seizure to make a diagnosis. For example, how often do the seizures occur? Is there a warning sign? Does the person remember anything about the seizure? All of these questions help the doctor to better understand the kind of seizures and therefore the kind of epilepsy that a person is experiencing. Witnesses to the seizure can be crucial to the diagnosis. By asking them to describe the seizure, valuable information can be learned. In instances where the patient does not remember the seizures, the observer may provide the only information.

Medical testing, such as EEG and MRI, are essential to understanding the cause of a person's seizures. EEG is a simple and painless study that records the brain's electrical activity. The brain waves are picked up by tiny electrodes that are applied to the person's scalp. Doctors then review the EEG, looking for specific brain wave patterns that happen during or between seizures in patients with epilepsy. These patterns provide critical information about the person's epilepsy and help with the diagnosis.

Imaging studies are also critical in understanding the cause of a person's seizures. The 2 most common types are MRI and $\mathrm{CT}$ scans. Modern CT and MRI provide very detailed pictures of the brain, and are critical in locating tumors, scars, or other abnormalities in the brain that may cause seizures.

\section{How Are Seizures Treated?}

There are many treatments for seizures. Medicines are tried first. If these do not work, the doctor may consider special diets, brain surgery, or implanted devices for the treatment of a patient's seizures. Usually, the physician tries to stop all seizures while causing no side effects. It is very important for patients experiencing seizures to tell their doctor about the kinds of problems they might experience while on a medication (or any treatment). Together, they can make the best choice of treatments.

\section{Seizures, Epilepsy, and Pregnancy}

First, it is important to know that women who have epilepsy can become pregnant. Most women with epilepsy have normal, healthy children. For women with epilepsy, the best time to see the neurologist is before they become pregnant. That way, the neurologist, the obstetrician, and the patient can work together to create the safest circumstances for the upcoming pregnancy. For women with epilepsy, there are 2 main issues to consider during pregnancy. First, how do seizures affect the developing baby? Second, how do medications affect the growing child? Seizures during pregnancy can cause falls and injuries. This can affect both mother and child. The type of seizure that is most worrisome during pregnancy is generalized tonic-clonic seizures. ${ }^{3}$ Studies have shown that control of this seizure type must be maintained throughout pregnancy. Because antiseizure drug levels change throughout pregnancy, levels are checked frequently, and medication doses are adjusted. The reason for this is simple: maintaining seizure control. The second issue is teratogenicity. In other words, do seizure medications cause birth defects? In order to study this, pregnancy registries were set up around the world several decades ago. Over the past 2 decades, scientists have learned much. One thing they have learned is that when it comes to different seizure medications, the drug valproate has the highest risk of causing birth defects when a baby is exposed to it in the 
womb. There seems to be an intermediate risk from the drugs phenobarbital and topiramate. The lowest risks are from carbamazepine, lamotrigine, levetiracetam, and oxcarbazepine. ${ }^{4}$

By understanding and discussing these concerns, doctors and patients can make the best-informed decisions.

\section{For More Information}

Brain \& Life

brainandlife.org

American Brain Foundation americanbrainfoundation.org

\section{Cure Epilepsy}

cureepilepsy.org

\section{American Epilepsy Society aesnet.org}

\section{References}

1. Voinescu PE, Pennell PB. Management of epilepsy during pregnancy. Expert Rev Neurother. 2015;15(10):1171-1187.

2. Voinescu PE, Ehlert AN, Bay CP, Allien S, Pennell PB. Variations in seizure frequency during pregnancy and postpartum by epilepsy type. Neurology. 2022;98(8):e802-e807.

3. Tomson T, Battino D. Pregnancy and epilepsy: what should we tell our patients? J Neurol. 2009;256(6):856-862.

4. Meador K. Teratogenicity and antiseizure medications. Epilepsy Curr. 2020;20(6 Suppl):15S-17S. 


\title{
Neurology
}

\author{
Seizure Worsening During Pregnancy: Who Is at Risk? \\ Steven Karceski \\ Neurology 2022;98;e876-e879 \\ DOI 10.1212/WNL.0000000000013286
}

This information is current as of February 21, 2022

\section{Updated Information \& Services}

\section{References}

Subspecialty Collections

Permissions \& Licensing

Reprints including high resolution figures, can be found at: http://n.neurology.org/content/98/8/e876.full

This article cites 4 articles, 1 of which you can access for free at: http://n.neurology.org/content/98/8/e876.full\#ref-list-1

This article, along with others on similar topics, appears in the following collection(s):

Autonomic diseases

http://n.neurology.org/cgi/collection/autonomic_diseases

Information about reproducing this article in parts (figures,tables) or in its entirety can be found online at:

http://www.neurology.org/about/about_the_journal\#permissions

Information about ordering reprints can be found online:

http://n.neurology.org/subscribers/advertise

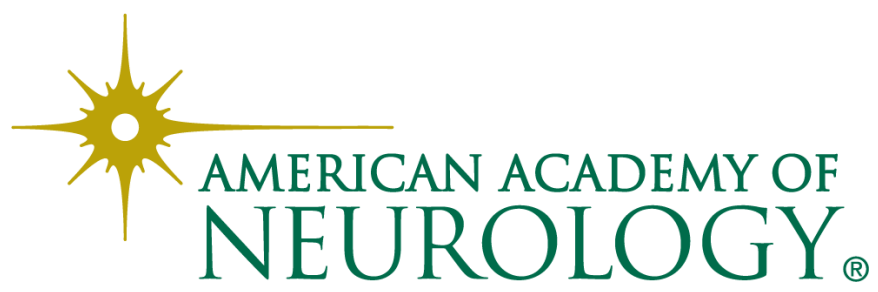

